\title{
OS DEVERES DO ESTADO NA PROTEÇÃO DO AMBIENTE
}

Rogério Santos Rammê*

\section{INTRODUÇÃO}

0 Estado de Direito Brasileiro, no que tange à proteção e garantia de direitos fundamentais, vem atravessando um momento de crise e de contestação por parte da população brasileira. A reivindicação por direitos cresce no cenário social brasileiro a cada dia, ao ritmo da globalização e das novas redes de conexão interpessoal de informação instantânea, desenvolvidas a partir do surgimento dasnovas tecnologias da informação e da comunicação.

Nesse contexto, a gravidade dos problemas políticos, sociais, econômicos, ambientais, morais e jurídicos, exige respostas rápidas e adequadas por parte dos operadores das ciências jurídicas e sociais, a quem impende à missão de construir uma perspectiva de conformação do direito a esses novos tempos. Não basta, apenas, pensar o direito ambiental como sistema ou ordenamento de normas jurídicas que objetivam assegurar direitos e exigir o cumprimento dos deveres, ou, ainda, atribuir e repartir competências estatais. É preciso, repensá-lo como um processo sociocultural

* Doutor em Direito (PUCRS). Mestre em Direito (UCS). Professor do Curso de Direito do Centro Universitário Metodista - IPA. Membro da comissão de Direito Ambiental da OAB/RS. Advogado. 
de regulação capaz de garantir a coexistência da vida em todas as suas formas tanto no presente quanto no futuro.

Identifica-se no âmbito do constitucionalismo pátrio uma recente inclinação doutrinária a apontar o surgimento de um marco jurídico-constitucional socioambiental, resultado da convergência necessária da tutela dos direitos sociais e dos direitos ambientais num mesmo projeto jurídico-político. Nele, ganha cada vez mais relevo a perspectiva da justiça ambiental e os demais valores do socioambientalismo, os quais desafiam o jurista desse tempo a compreender o âmbito de proteção dos direitos e deveres fundamentais socioambientais, bem como a buscar estratégias jurídicas capazes de garantir sua concretização.

Nesse cenário foi desenhada a presente narrativa, que toma a socioambientalidade como ponto de partida para a construção de uma reflexão sobre os deveres de proteção de um Estado Socioambiental e Democrático de Direito na proteção do ambiente, enfatizando seu regime jurídico constitucional.

\section{O PROJETO JURÍDICO-CONSTITUCIONAL SOCIOAMBIENTAL BRASILEIRO}

A partir da promulgação da Constituição Federal de 1988, e com o amadurecimento de uma leitura constitucional da tutela do ambiente, novas reflexões e percepções surgiram no cenário jurídico-doutrinário brasileiro, identificando o projeto de uma nova ordem jurídico-ecológica, capaz de tornar convergentes as agendas social e ambiental por meio de uma adequada regulação constitucional socioambiental.

Expoentes dessa abordagem, Sarlet e Fensterseifer (2010, p. 13) referem que a nova ordem constitucional brasileira é inovadora ao estabelecer claramente a opção por um novo modelo de Estado "Socioambiental" de Direito, o qual resulta de uma convergência da tutela dos direitos sociais e dos direitos ambientais em um mesmo projeto jurídico-político, voltado ao 
desenvolvimento humano em padrões sustentáveis. Inclui-se nesse projeto jurídico-político socioambiental, portanto, uma noção abrangente e integrada dos direitos econômicos, sociais, culturais e ambientais (DESCA). Os autores suprarreferidos destacam, assim, o surgimento de um constitucionalismo socioambiental, ou ao menos a necessidade de se construir tal noção jurídica, que avança para além do constitucionalismo social.

Esse constitucionalismo socioambiental também pode ser compreendido como um reflexo da contaminação, no espaço jurídico-político, de valores ecológicos e de princípios de justiça ambiental ${ }^{1}$. Este, aliás, é o grande desafio do Estado Socioambiental de Direito contemporâneo: tornar-se um modelo de Estado onde os valores ecológicos e os princípios de justiça ambiental tornem-se referenciais normativos permanentes, em todas as esferas de atuação estatal.

O Estado Socioambiental de Direito não pode ser indiferente às práticas discriminatórias que onerem de forma injusta o modo de vida, o território, a cultura, as tradições e a saúde de indivíduos ou comunidades humanas, em virtude de raça, condição socioeconômica, localização geográfica, dentre outros fatores (aí a dimensão sociocultural da proteção ambiental); mas também não pode ser indiferente às relações ecológicas que dão sustentação à vida no planeta Terra (dimensão ecológica da proteção do ambiente). Esse último aspecto da proteção do ambiente é onde se insere o dever fundamental ecológico e as obrigações dele decorrentes.

Um dos caminhos que a doutrina especializada vem trilhando para identificar o marco normativo desse novo modelo de Estado passa pela redefinição do conceito de dignidade humana, que passa a ser concebido como dotado de dupla dimensão, social e

1 Por princípios de justiça ambiental, compreenda-se todo um "[...] conjunto de princípios que asseguram que nenhum grupo de pessoas, sejam grupos étnicos, raciais ou de classe, suporte uma parcela desproporcional de degradação do espaço coletivo" (ACSELRAD; HERCULANO; PÁDUA, 2004. p. 10-11). 
ecológica. A dimensão social (ou comunitária) da dignidade da pessoa humana, como referem Sarlet e Fensterseifer (2013, p. 71), implica um permanente "[...] olhar para o outro, visto que o indivíduo e a comunidade são elementos integrantes de uma mesma (e única) realidade político-social”.A dimensão social da dignidade da pessoa humana, portanto, enfatiza não apenas um compromisso moral, mas também jurídico do Estado e dos particulares para com a construção de uma estrutura político-social que assegure um mínimo existencial social para a vida humana com dignidade. Já a dimensão ecológica da dignidade humana não se restringe a algo puramente biológico ou físico, mas contempla, segundo Sarlet e Fensterseifer (2013, p. 72), “[...] a qualidade de vida como um todo, inclusive do ambiente em que a vida humana (mas também a não-humana) se desenvolve". A dimensão ecológica da dignidade humana, portanto, amplia o conteúdo da dignidade da pessoa humana de modo a assegurar um padrão de qualidade e segurança ambiental mais elevado aos seres humanos.

Dessa remodelação do conceito de dignidade humana exsurge a ideia de um mínimo existencial ecológico. Sobre isso, Sarlet e Fensterseifer (2010, p. 14) observam:

[...] para além dos direitos já identificados doutrinariamente como "possíveis" integrantes da noção de um mínimo existencial (reconhecidamente controversa, a despeito de sua popularidade), como é o caso de uma moradia digna, de assistência social, de uma alimentação adequada, entre outros, é nosso intento sustentar a inclusão nesse elenco da qualidade ambiental, objetivando a garantia de uma existência humana digna e saudável, especialmente no que diz com a construção de um bem-estar existencial que tome em conta também a qualidade do ambiente.(grifo dos autores) 
Em essência, o mínimo existencial ecológico se traduz num princípio basilar do Estado Socioambiental e Democrático de Direito. Decorre, sobretudo, do reconhecimento da fundamentalidadedo direito ao ambiente ecologicamente equilibrado e da constatação de como os atuais processos de degradação ambiental atingem em cheio a dignidade da vida humana. Com efeito, para além de um mínimo existencial social, o mínimo existencial ecológico adquire notoriedade como um padrão mínimo de qualidade ambiental para a concretização da dignidade de indivíduos e coletividades humanas. Esse padrão mínimo de qualidade ambiental só será alcançado e assegurado a todos os indivíduos se efetivamente forem compreendidas e cumpridas as obrigações que decorrem do dever fundamental ecológico. Cabe destacar que a edificação desse Estado Socioambiental de Direito também passa pela consolidação e reconhecimento de direitos e deveres fundamentais socioambientais, os quais decorrem de uma compreensão integrada e interdependente dos direitos e deveres econômicos, sociais, culturais e ambientais.

Os direitos e deveres fundamentais socioambientais se apresentam como uma resposta necessária do constitucionalismo contemporâneo à problemática socioambiental que se reflete, como bem observa Leff (2001), em uma crise civilizacional, na qual o sonho dourado do desenvolvimento e modernização, guiado pelo crescimento econômico e pelo progresso tecnológico, apoia-se em um regime jurídico forjado por uma ideologia de liberdades individuais que privilegia os interesses privados em detrimento dos coletivos. Os direitos e deveres fundamentais socioambientais emergem, portanto, da crise socioambiental contemporânea, do "grito" da natureza e das lutas sociais que reivindicam justiça em processos de degradação social e cultural por meio da exploração do ambiente. Seu fortalecimento, portanto, decorre de uma exigência de respeito às identidades étnicas forjadas ao longo da história de um povo e da relação travada com seu entorno ecológico. 
Essa perspectiva socioambiental que caracteriza o projeto de sociedade estabelecido pela $\mathrm{CF} / 88$, possui inegável valor. Nessa perspectiva, inclusive, fundamenta-se o conceito amplo de ambiente adotado por esmagadora doutrina do direito ambiental pátrio, a incorporar não apenas o ambiente natural, mas tudo que rodeia e cerca o ser humano, abrangendo o ambiente artificial, o ambiente cultural e o ambiente do trabalho.

\section{A PROTEÇÃO DO AMBIENTE COMO DIREITO-DEVER FUNDAMENTAL E SUA DUPLA DIMENSÃO}

A seguir, procurar-se-á tecer um panorama geral do status jurídico da proteção do ambiente no ordenamento constitucional brasileiro, aproveitando abordagens doutrinárias estrangeiras que levantam questões polêmicas que, em virtude da semelhança na forma com a qual a maioria das Constituições ocidentais trata a proteção do ambiente, podem gerar alguma inquietação no âmbito jurídico interno.

De início, cumpre examinar a existência da dúplice dimensão (subjetiva e objetiva) do direito fundamental ao ambiente, passando por diferentes posições doutrinárias, eventualmente divergentes, sobre esse tema. Muito embora se possa imaginar haver uma relativa unidade de entendimento, uma análise doutrinária mais aprofundada, sobretudo à luz do direito comparado, permite compreender que diferentes posições são sustentadas, inclusive no sentido de negar a existência de um direito (subjetivo) fundamental ao ambiente.

Segundo Gomes (2007, p. 27-30), a fórmula do direito ao ambiente revela uma operatividade nula, porquanto entende que seu reconhecimento não surte efeitos para além do simbólico e do pedagógico. Em defesa de sua tese, Gomes ampara-se em argumentos de diversos autores do cenário jurídico internacional, concluindo que o reconhecimento de um direito ao ambiente apresenta uma série de obstáculos estruturais que o inviabili- 
zam, tais como: (a) a identificação do bem jurídico protegido pelo pretenso direito, ou seja, o direito ao ambiente, ao fim e ao cabo, se materializa no direito à vida ou no direito à integridade física (na vertente do direito à saúde), os quais são típicos direitos de personalidade já consagrados que acabam por lhe absorver e anular em autonomia; (b) a identificação do titular da prestação do direito, afinal se o direito ao ambiente é algo que está além do direito à vida de cada indivíduo, seu objeto estaria em um plano comunitário, dificultando a identificação do titular do direito subjetivo; e (c) a abstração conceitual da noção de qualidade de vida, porquanto, mesmo que se reconheça no direito ao ambiente um direito à qualidade de vida, estar-se-á diante de uma obrigação exigível de cada Estado, em função de condicionantes objetivas (economia, geografia, cultura etc.), mas não de um direito subjetivo invocável individualmente.

Nem mesmo a tentativa de atribuir um sentido essencialmente procedimental ao direito do ambiente é vista por Gomes como algo capaz de salvá-lo da adjetivação de "fórmula vazia". Isso porque essa suposta dimensão procedimental do direito ao ambiente - consubstanciada nos direitos de acesso à informação, à participação e à justiça em matéria ambiental -, segundo a autora, na verdade, são direitos procedimentais específicos que têm aplicação geral na maioria das convenções e declarações internacionais de direitos humanos. Em síntese, Gomes conclui que a via da subjetivação da tutela ambiental pelo reconhecimento de um direito fundamental ao ambiente se revela uma fórmula não apenas inútil, em razão da sobreposição com posições jurídicas já consagradas, como também deficitária, já que a tutela ambiental fica sempre adstrita às necessidades individuais humanas, inviabilizando uma reparação puramente ecológica, desvinculada de interesses humanos. Em razão disso, Gomes entende que a única via possível da subjetivação da tutela ambiental, numa perspectiva solidarista que reveste a tutela dos bens coletivos, se dá pelo 
reconhecimento de um dever de proteção do ambiente (GOMES, 2007, p. 99-100).

Essa argumentação ganha força quando analisada a resistência que ainda hoje se verifica no âmbito do direito internacional público com relação ao reconhecimento de um direito humano ao ambiente sadio e ecologicamente equilibrado. Muito embora seja inegável que a luta pela proteção do ambiente está inserida em um contexto que não é distinto daquele da luta por direitos humanos - embora nele não se esgote - e que diversos autores nacionais e estrangeiros sustentem a existência do direito humano ao ambiente, a partir de uma perspectiva historicista dos direitos humanos, a questão não é de todo pacífica.

Isso se deve ao fato de que os regimes de proteção internacional dos direitos humanos e dos direitos ambientais ao longo das últimas décadas desenvolveram-se, a par da íntima relação e dos pontos de contato existentes, separadamente, gerando lacunas que até hoje carecem de uma melhor sistematização.0 Sistema Interamericano de Direitos Humanos é um bom exemplo. Segundo Courtis (2007, p. 113), no âmbito do Sistema Interamericano a vinculação entre direitos humanos e proteção do ambiente é um "terreno movediço", onde quase tudo está por ser feito. Courtis chega a sugerir que em virtude da ausência efetiva do reconhecimento do direito ao ambiente como um direito justiciável no âmbito do Sistema Interamericano de Direitos Humanos, a melhor forma de salvaguardar interesses ambientais junto à Corte Interamericana de Direitos Humanos é por meio de estratégias indiretas de litígio, invocando outros direitos humanos (substantivos ou adjetivos) igualmente violados em casos de degradação do ambiente.

Contudo, como ressaltado, inúmeras têm sido as abordagens teóricas que se propõe a traçar um paralelo dos sistemas de proteção internacional na tentativa de fortalecer o reconhecimento do direito ao ambiente como direito humano. Nesse particular, em nível nacional, inegável destaque deve ser dado a Trindade 
(1993), que já a mais de duas décadas atrás se preocupava em desenvolver uma abordagem teórica de aproximação entre os sistemas de proteção internacional dos direitos humanos e dos direitos ambientais. É possível identificar na doutrina de Trindade diversos fundamentos que influenciaram direta ou indiretamente o constitucionalismo ambiental brasileiro contemporâneo. Aspecto importante, e que aqui nos interessa em especial, diz com a posição de Trindade acerca dos sujeitos e do objeto de proteção do direito ao ambiente, onde se percebe claramente a posição do autor a respeito da existência de uma dupla dimensão (subjetiva e objetiva) desse direito, bem como da sua interação ou integração com outros direitos individuais e sociais pré-existentes.

Também é inegável que a doutrina jurídico-constitucional estrangeira foi e ainda tem sido igualmente decisiva no desenvolvimento do marco jurídico-constitucional voltado à proteção do ambiente no Brasil. Especificamente no que se refere à discussão acerca da existência ou não de um direito (subjetivo) ao ambiente sadio e equilibrado, merece especial ênfase o debate travado na Europa, em países como Alemanha, Portugal e Espanha, nos quais o tema ganhou maior destaque. ${ }^{2}$

Na Alemanha, Alexy (2008, p. 443) sustenta que o direito fundamental ao ambiente se caracteriza por ser um "direito fundamental completo", porquanto composto por "um feixe de posições de espécies bastante distintas", as quais podem incorporar direitos de defesa, direitos de proteção, direitos a procedimentos e direitos a prestações fáticas.

De ressaltar que o ordenamento jurídico alemão, até o ano de 1994, não dispunha de um preceito constitucional especifica-

\footnotetext{
No cenário Europeu, o tema também ganhou importante destaque na Itália, sobretudo pelo fato de a Constituição italiana não fazer menção expressa a um direito ao ambiente, consagrando apenas o direito à saúde e a tarefa estatal de proteção da paisagem (artigos 32 e 9 respectivamente). Segundo Gomes, tal fato conduziu boa parte da doutrina e a jurisprudência italianas a enveredar pela via da subjetivação da proteção do ambiente. (GOMES, 2007,p. 45-50)
} 
mente dedicado à proteção ambiental, o que induzia uma tutela do ambiente pela via da subjetivação, vinculada a direitos fundamentais como a vida, a integridade física, a propriedade etc. Entretanto, em 1994, foi inserido o artigo 20-A na Lei Fundamental da Alemanha, que qualifica de forma expressa a proteção do ambiente como uma tarefa fundamental do Estado.Desde então, afirma Gomes (2007, p. 52), parte da doutrina alemã converge na afirmação da proteção do ambiente como tarefa do Estado e desaconselha a subjetivação.

Segundo Kloepfer (2010, p. 50), a atual sistemática constitucional alemã a tarefa estatal de proteção do ambiente dirige-se aos três Poderes do Estado, fixando uma proibição de retrocesso (Rückschrittsverbot) e garantindo padrões ecológicos mínimos, ou seja, uma ecologização (Ökologisierung) do sistema jurídico alemão. Importante salientar que Kloepfer (2010, p. 46), muito embora reconheça a forte indeterminabilidade de conteúdo do direito subjetivo ao ambiente, admite-o como derivativo do princípio do Estado social, "[...] na medida em que se trata da asseguração do mínimo existencial ecológico".

Em Portugal, a posição de Gomes - que, como visto, nega a dimensão subjetiva do direito ao ambiente - não corresponde a da doutrina majoritária. Para Canotilho (2008, p. 4), a inclusão, na Constituição da República de Portugal, no catálogo dos direitos econômicos, sociais e culturais, do direito a um ambiente de vida humano sadio e ecologicamente equilibrado (art. 66을 da CRP), revela a opção dos constituintes portugueses de reconhecer no direito ao ambiente a natureza de direito fundamental subjetivo.Contudo, não indiferente à crítica contrária, pondera Canotilho (2008, p. 4):

Independentemente de saber se o direito ao ambiente é um verdadeiro direito subjectivo, tornou-se claro que a problematização constitucional deste direito não deveria limitar-se ao recorte do ambiente como tarefa fundamental do Estado. A 
orientação jussubjectiva da Constituição Portuguesa é tanto mais de assinalar quanto se assiste, ainda hoje, à elaboração de robustas posições doutrinárias contra a jusfundamentalização ambiente. Precisamente por isso, a primeira ideia forte do enquadramento jurídico-constitucional do ambiente é a de que no ordenamento jurídico português a conformação jurídico-subjectiva do ambiente é indissociável da sua conformação jurídico-objectiva.

Semelhante é a posição do constitucionalista português Pereira da Silva (2002). Muito embora o autor defenda a ideia de que a defesa do ambiente é tarefa estatal, reconhece o direito ao ambiente como um direito subjetivo fundamental completo do qual emanam distintas posições jurídicas -, axiologicamente radicado no princípio da dignidade da pessoa humana e dotado de uma dupla faceta, defensiva e prestacional. Segundo o autor, uma coisa é a tarefa objetiva de proteção do ambiente e outra, distinta, é a proteção jurídica subjetiva ambiental, a qual decorre “[...] da existência de um domínio individual constitucionalmente protegido de fruição ambiental, que protege o seu titular de agressões ilegais provenientes de entidades públicas (e privadas)" (PEREIRA DA SILVA, 2002, p. 95).

Ainda no âmbito do direito constitucional português, merecem especial destaque as posições de Miranda e Vieira de Andrade sobre o tema em questão. Para Miranda (2000, p. 534), a base da subjetivação do direito fundamental ao ambiente não reside propriamente no artigo 66으 da Constituição da República de Portugal, mas sim na possibilidade, prevista no artigo 52으 da Constituição portuguesa, de todo e qualquer cidadão português requerer a tutela judicial preventiva e ressarcitória em face de condutas lesivas ao ambiente. Já para Vieira de Andrade (2012, p. 158) o direito ao ambiente é um direito de solidariedade que não se limita a uma intervenção prestacional do Estado, nem à 
exigência de respeito a um bem próprio individual, mas trata-se de um verdadeiro "direito circular", cujo conteúdo define-se essencialmente "[...] em função do interesse comum, pelo menos em tudo que aquilo que ultrapassa a lesão direta de bens individuais."

Na Espanha, ao comentar o artigo 45 da Constituição espanhola, Giménez (2002) afirma que o ordenamento constitucional espanhol reconheceu a proteção do ambiente como um direito e um dever, elevando-a a categoria de princípio orientador da política social e econômica daquele país. Assim, Giménez insere o direito ao ambiente no rol dos direitos fundamentais de terceira dimensão, que têm na solidariedade o seu valor guia. Especificamente sobre a subjetivação do direito ao ambiente, Giménez reconhece a resistência de parte da doutrina em aceitar a ideia de que o artigo 45 da Constituição da República da Espanha diga respeito a um direito fundamental ao meio ambiente. Contudo, para a autora, ao invés de negar a dimensão subjetiva do direito ao ambiente, reconhecendo exclusivamente sua dimensão objetiva, mais proveitoso é aprofundar o conceito de direitos de terceira geração ou de solidariedade, os quais se caracterizam por levarem implícitos o dever de sua proteção (GIMÉNEZ, 2002, p. 78).

Também no âmbito do constitucionalismo espanhol, reconhecendo o direito subjetivo ao ambiente, destaca-se a posição de Echevarria (2005, p. 33-45). Para o autor, o direito ao ambiente é um direito dotado de fundamentalidade material que também se justifica sob o ponto de vista de um direito individual (subjetivo), notadamente por ser imprescindível ao desenvolvimento da pessoa e por manter relação direta com o princípio da dignidade da pessoa humana.

Em sentido oposto, parte da doutrina constitucional espanhola se inclina para a qualificação da norma do artigo 45 da Constituição da Espanha como concretização de um princípio fundamental de atuação do Estado na proteção dos bens ambientais naturais (água, ar, solo, fauna e flora).Um dos adeptos dessa vertente doutrinária 
na Espanha é Pérez Luño (2005). Para esse autor, muito embora a sobrevivência da espécie humana, cada vez mais ameaçada pela degradação do ambiente, constitua um valor prioritário para qualquer sociedade, isso não implica o reconhecimento de um direito fundamental ao ambiente. Assim, as técnicas de positivação dos direitos fundamentais exigem que eles se refiram a situações jurídicas bem determinadas quanto ao seu objeto e titularidade, o que não ocorre com o pretenso direito fundamental ao ambiente, dada a dificuldade de se estabelecer com precisão o seu conjunto de faculdades constitutivas (PÉREZ LUÑO, 2005, p. 455). Nesse sentido, defende a tutela do ambiente essencialmente como finalidade dos Estados Constitucionais (PÉREZ LUÑO, 2012).

Por fim, também no âmbito do direito constitucional espanhol, destaca-se a posição de Yarza (2012). Para esse autor resulta impraticável reconhecer a existência de um direito autônomo ao meio ambiente, devido ao objeto desse pretenso direito ser um bem jurídico de caráter coletivo. Contudo, esclarece que issonão implica que o ambiente careça de relevânciajusfundamental. Aocontrário, para Yarza (2012, p. 97), o interessenaproteção do ambiente pode se conectar à interesses e bens jurídicos individuais, influindo decisivamente nainterpretação e aplicação dos direitos que daídecorram.Dessa forma, Yarza adota clara posição no sentido de que a conexão entre os direitos fundamentais e o meio ambiente pode adotar múltiplas formas, não somente pelos distintos bens jurídicos que são afetados por essa relação, mas também pelas distintas categorias jurídico-fundamentais que essa relação pode traduzir.

No Brasil, há praticamente um consenso doutrinário a respeito do reconhecimento da dupla funcionalidade da proteção do ambiente: tanto objetivo e tarefa do Estado, quanto direito e dever fundamental dos indivíduos que integram a comunidade estatal.

A posição defendida por Sarlet e Fensterseifer (2012, p. 14) é clara no sentido de reconhecer a existência da dimensão subjetiva 
da proteção do ambiente, ou seja, de um direito fundamental ao ambiente ecologicamente equilibrado, que se caracteriza por ser um "conjunto diferenciado e complexo de posições subjetivas". Os autores, à luz do regime jurídico-constitucional da proteção do ambiente no Brasil, igualmente identificam a dimensão objetiva do direito fundamental ao ambiente, a qual guarda íntima relação com a imposição, aos particulares, de deveres fundamentais em matéria ambiental, bem como com o objetivo e tarefa estatal de proteção e promoção do equilíbrio ambiental (SARLET; FENSTERSEIFER, 2012, p. 13). Como objetivo e tarefa do Estado, a proteção ambiental assume a forma de deveres de proteção, os quais, segundo Mendes (2004), são deveres que se impõem ao Estado para evitar riscos, autorizando o Poder Público a atuar em defesa do cidadão mediante a adoção de medidas de proteção ou prevenção.

Em semelhante sentido, Benjamin (2008) reconhece a fundamentalidade do direito ao ambiente, o qual se alicerça nos valores da "fraternidade" ou "solidariedade. Na visão de Benjamin, o direito fundamental ao ambiente sadio e equilibrado tem estrutura bifronte (negativa, associado a um non facere; e positiva, exigindo prestações positivas do Estado e da sociedade). É direito de exercício coletivo, mas também individual, “[...] não se perdendo a característica unitária do bem jurídico ambiental - cuja titularidade reside na comunidade ('todos') - ao reconhecer-se um direito subjetivo ao meio ambiente ecologicamente equilibrado (BENJAMIN, 2008, p. 103).

Destaca-se também a posição de Medeiros (2004), desenvolvida em obra específica sobre o tema, na qual sustenta, a partir de uma interpretação sistemática da proteção constitucional do ambiente, e com forte influência das doutrinas constitucionais germânica e portuguesa, que a proteção constitucional do ambiente no Brasil traduz um típico direito-dever fundamental. Assim, defende que a proteção do ambiente é tanto um direito fundamental, dotado de dupla função (defensiva e prestacional), 
quanto um dever fundamental de cunho positivo e negativo (MEDEIROS, 2004, p.114-130).

Não menos relevante é a posição defendida por Krell (2013), ao analisar o artigo 225, caput, da Constituição Federal brasileira. Segundo o autor, o referido dispositivo constitucional consagrou a proteção do ambiente tanto como tarefa fundamental do Estado (seja como "norma-fim" direcionada ao poder estatal, seja como "tarefa estatal disfarçada" cuja concretização dependa de intervenção do Poder Público), quanto como direito público subjetivo, ainda que não seja típico, ou seja, divisível, particularizável ou desfrutável individualmente. Para o autor, somente por meio do reconhecimento constitucional de um direito subjetivo ao ambiente equilibrado é que se torna possível reconhecer no equilíbrio ecológico do ambiente um bem jurídico autônomo, não dissolvido na proteção de outros bens jurídicos relevantes. Essa dimensão jurídico-subjetiva do direito ao ambiente, porém, guarda íntima correlação com sua dimensão jurídico-objetiva. Assim, muito embora a dimensão subjetiva enfatize o caráter individualista do direito ao ambiente, isso em nada diminui sua dimensão coletiva ou social (KRELL, 2013, p. 2082).

Com efeito, traçado um panorama geral dos principais argumentos doutrinários a favor e contra da vertente subjetiva da proteção constitucional do ambiente, adota-se a posição em favor do reconhecimento da proteção do ambiente como típico "direito-dever" fundamental, dotado de uma dupla dimensão subjetiva e objetiva. Trata-se de um típico direito-dever fundamental, porquanto ambos - o dever e o direito - possuem conteúdo (proteção do equilíbrio ecológico do ambiente) conexo, coligado, muito embora devam ser compreendidos como realidades jurídicas autônomas. A dimensão subjetiva do direito fundamental ao ambiente, se caracteriza por um feixe de posições jurídicas de vantagem, cuja tutela pode ser individualmente reivindicada, muito embora diga respeito a um bem jurídico que é essencial- 
mente coletivo. Já a dimensão objetiva do direito fundamental ao ambiente, implica uma mais-valia jurídica à sua dimensão subjetiva, a saber: (a) a eficácia irradiante do direito fundamental ao ambiente a exigir uma aplicação e interpretação a ele conforme; (b) a eficácia horizontal (Drittwirkung) do direito fundamental ao ambiente no âmbito das relações privadas e não apenas em face dos poderes públicos; (c) os deveres de proteção do Estado em matéria ambiental; (d) consequências nos planos organizacional e procedimental que auxiliem na efetivação e proteção do direito fundamental ao ambiente.

Por outro lado, a esfera do dever fundamental decorre da incorporação pelo ordenamento constitucional brasileiro da proteção ambiental como um valor comunitário fundamental e essencial à sadia qualidade da vida humana. Ele decorre essencialmente, portanto, de uma perspectiva objetiva da proteção do ambiente, muito embora também implique efeitos subjetivos, consubstanciados na imposição de obrigações que se impõem a todos os indivíduos na consecução do objetivo comum da proteção do ambiente.

\section{A JUSTIFICAÇÃO DOS DEVERES DE PROTEÇÃO DO ESTADO EM MATÉRIA AMBIENTAL}

De um modo geral, como já afirmamos, a temática dos deveres fundamentais é ainda pouco abordada pela doutrina nacional. Mesmo a doutrina estrangeira acerca-sedo tema com reservas, sendo raros os autores que se dedicam a um enfrentamento aprofundado do assunto.

Nabais (2009) aponta as razões para o esquecimento do tema pela doutrina constitucional contemporânea, citando o próprio sentido originário da ideia de Estado, que objetivava, através do direito, manter o exercício do poder dentro de determinados limites, assegurando assim a liberdade e autonomia individuais. Isso levou a primazia por direitos subjetivos públicos, como posições jurídicas ativas dos titulares em face do poder do Estado. 
Segundo a lição de Hesse (2009), pertence à tradição dos direitos fundamentais a ideia de que eles não são apenas direitos subjetivos, mas ao mesmo tempo representam princípios objetivos da ordem constitucional. Ou seja, em um Estado de Direito os direitos fundamentais, além de atuarem como limites da ação estatal, obrigam o Estado a proteger seus conteúdos jusfundamentais mediante procedimentos adequados; portanto, a compreensão dos direitos fundamentais como princípios objetivos adquire uma importância decisiva no âmbito das tarefas do Estado, na medida em que vinculam os Poderes Legislativo, Executivo e Judiciário a esses direitos, não apenas de forma negativa (abstenção de ingerências no âmbito protegido pelos direitos fundamentais), mas também de forma positiva (levar a cabo tudo que seja necessário para a realização dos direitos fundamentais).

Esse efeito de irradiação dos direitos fundamentais, com força conformadora, tem sua raiz jurisprudencial na relevante decisão do casoLüth do Bundesverfassungsgericht de 1958. Essa paradigmática decisão reconheceu o conteúdo jurídico-objetivo dos direitos fundamentais e sua irradiação para toda a ordem jurídica, acrescentando à tradicional eficácia vertical (Estado-cidadão) das normas de direito fundamental, uma eficácia horizontal - entre terceiros (os particulares), bem como lançou luzes definitivas para uma nova concepção da ordem constitucional fundada em um sistema objetivo de valores centrado necessariamente na dignidade da pessoa humana (SARLET, 2012). Nesse quadro de irradiação inclui-se o encargo constitucional do Estado de Direito de prover as condições objetivas mínimas para o efetivo exercício dos direitos fundamentais.

Mas quais seriam os princípios inspiradores da doutrina dos deveres de proteção jusfundamentais? Fernando SimónYarza (2012) nomeia-os: (a) princípio da segurança, que traduz a ideia de que não basta ao Estado a não intervenção na esfera de liberdade dos indivíduos, mas também se faz necessária uma função estatal 
protetora dos direitos fundamentais contra as invasões privadas, calcada numa ideia de segurança social; e (b) princípio do Estado social, que complementa o princípio da segurança, ampliando o aspecto protetivo dos direitos fundamentais, para além da proteção frente a terceiros, voltado à proteção do indivíduo contra aquelas ameaças que recaem sobre seu âmbito vital efetivo e contra as quais o indivíduo sozinho não tem condições de defender-se, como por exemplo, a proteção frente a certos riscos ambientais.

No entanto, Yarza (2012) admite que os referidos princípios constituem tão somente uma inspiração material para os deveres de proteção jusfundamentais, não servindo, porém, para o fim de criar obrigações justiciáveis. Em outras palavras, não traduzem um elenco de deveres de proteção estatal. Para esse fim, faz-se necessária uma análise jurídica constitucional mais densa sobre como se fundamentam os deveres de proteção em concreto.

Uma forma de fundamentar a existência de deveres de proteção jusfundamentais parte da literalidade de certas normas atributivas de direitos, ou seja, decorre de preceitos que não apenas reconhecem direitos, como também os protegem e garantem. Porém aqui, o cuidado reside, segundo Yarza (2012), em não extrapolar a interpretação literal do âmbito de proteção concretizado no texto constitucional.

Também a perspectiva dasolução jurídico-defensiva(abwehrrechtlicheLösung), em sua matriz teórico-discursivapode ser utilizada para fundamentar os deveres jusfundamentais de proteção do Estado. Trata-se de tese que se baseia no fato de o Estado intervir de diferentes modos nas atividades dos sujeitos privados, seja financiando-as, seja submetendo-as a autorizações, o que permite imputar a ele uma responsabilidade pelo correto exercício das atividades privadas e uma culpa (in vigilando) quando esse exercício seja lesivo. Porém, essa tese é alvo de inúmeras críticas que argumentam que o simples fato de uma ação ou atividade não estar proibida, e sim permitida ou autorizada, 
não fundamenta uma participação do Estado na sua realização, não se podendo, portanto, imputar ao Estado uma conduta lesiva que decorra da atividade, exceto na hipótese de uma neutralidade negligente que tenha por base um dever de proteção prévio (YARZA, 2012, p.113).

O compartilhamento daresponsabilidade do Estado relativamente às atividades perigosas decorrentes do dever do Estado de proteção dos direitos fundamentais na fórmula germânica (Grundrechtliche Schutzpflichten des Staates), também fundamenta a existência de deveres de proteção. Trata-se aqui de imputar ao Estado uma posição especial de garante, impondo-lhe uma responsabilidade por uma adequada regulação das atividades de risco (YARZA, 2012). Ou seja, reconhece-se ao Estado a existência de um dever de proteção especialmente intenso no âmbito das atividades perigosas.

Mas os fundamentos mais robustos a justificar os deveres de proteção são os que concebem os deveres de proteção como conteúdo jurídico-objetivo dos direitos fundamentais, ou seja, emanações de valor ou de princípio jusfundamentais; bem como aqueles que fundamentam, sem exceder os limites do texto constitucional, a existência de um dever de proteção à dignidade humana, baseado na existência de um núcleo de dignidade humana que é garantido pelos direitos fundamentais e que impõe a obrigação estatal de uma proteção essencial dos bens vitais mais básicos.

Tecidas essas observações, parte-se para uma análise mais apurada dos deveres de proteção do Estado brasileiro em matéria ambiental, tendo em vista o marco jurídico-constitucional vigente.

\section{OS DEVERES DE PROTEÇÃO DO ESTADO EM MATÉRIA AMBIENTAL À LUZ DO REGIME JURÍDICO-CONSTITUCIO- NAL BRASILEIRO}

A proteção da integridade dos bens ambientais é, inegavelmente, uma missão de natureza pública. Ou seja, há um flagrante 
interesse público primário no desenvolvimento de ações políticas, administrativas, legislativas e jurídicas de tutela ambiental, quer por imperativo constitucional expresso, quer pela carga valorativa jurídico-objetiva que emana do direito fundamental ao ambiente ecologicamente equilibrado (no caso do Brasil, expressamente reconhecido no art. 225 da $\mathrm{CF} / 88$ ).

Como demonstrado, os deveres de proteção do Estado em matéria ambiental igualmente vinculam-se à dimensão objetiva do direito fundamental ao ambiente, a qual traduz novos valores ecológicos que passaram a ser incorporados no cenário políticocomunitário contemporâneo, muito em decorrência da importância que a temática ambiental alcançou em âmbito internacional.

0 reconhecimento dessa dimensão objetiva do direito fundamental ao ambiente e dos deveres de proteção estatais correlatos implica efeitos positivos específicos, bem destacados por Krell (2013):(a) reduz o espaço da livre conformação do legislador ordinário em todos os níveis da federação, na elaboração das normas relacionadas com aspectos ambientais; (b) impõe aos parlamentares que sempre levem em consideração a proteção ambiental no que se refere à regulamentação das atividades públicas e privadas de todas as áreas da vida social; (c) influencia uma adequada interpretação axiológica das leis ordinárias e do exercício do poder discricionário da Administração Pública; (d) impõe que o Poder Público, na formulação de políticas públicas, sempre opte pela alternativa menos gravosa ao ambiente; (e) conduz à proibição de retrocesso ambiental, vetando ao Poder Público a adoção de medidas que reduzam o nível da proteção normativa do ambiente já alcançado sem legítimas razões;(f) implica a judicialização da proteção ao mínimo existencial ecológico, núcleo essencial do direito fundamental ao ambiente e à sadia qualidade de vida.

Inegavelmente, os destinatários dos deveres de proteção em matéria ambiental são o Estado, como destinatário geral, e seus 
Poderes (Legislativo, Executivo e Judiciário) como destinatários específicos, aptos a implementar as medidas concretizadoras de proteção.

Na perspectiva dos deveres fundamentais socioambientais, cita-se o art. 225 da Carta de 1988, que ocupa topo central no espaço jurídico ambiental ao dispor que "Todos têm direito ao meio ambiente ecologicamente equilibrado, [...] impondo-se ao Poder Público e à coletividade o dever de defendê-lo e preservá-lo para as presentes e futuras gerações." Nesse sentido, para assegurar tal direito constituem, entre outros, deveres do Estado (Art. 225, $\S 1$ o, e incisos, da CF/88): (a) preservar e restaurar os processos ecológicos essenciais e prover o manejo ecológico das espécies e ecossistemas; (b) preservar a diversidade e a integridade do patrimônio genético do País e fiscalizar as entidades dedicadas à pesquisa e manipulação de material genético; (c) definir, em todas as unidades da Federação, espaços territoriais e seus componentes a seremespecialmente protegidos, sendo a alteração e a supressão permitidas somente através de lei, vedada qualquer utilização que comprometa a integridade dos atributos que justifiquem sua proteção;(d) exigir, na forma da lei, para instalação de obra ou atividade potencialmente causadora de significativa degradação do meio ambiente, estudo prévio de impacto ambiental, a que se dará publicidade;(e) controlar a produção, a comercialização e o emprego de técnicas, métodos e substâncias que comportem risco para a vida, a qualidade de vida e o meio ambiente;(f) promover a educação ambiental em todos os níveis de ensino e a conscientização pública para a preservação do meio ambiente; $(\mathrm{g})$ proteger a fauna e a flora, vedadas, na forma da lei, as práticas que coloquem em risco sua função ecológica, provoquem a extinção de espécies ou submetam os animais à crueldade. A esse respeito, observa-se que: 
A Constituição brasileira, desta forma, privilegia uma estrita modalidade de posições jurídicas, pois ou são direitos-deveres (ou deveres-direitos pendente a posição do sujeito) de proteção, articulando os direitos subjetivos de sujeitos singulares e plurais, e na esfera pública, tarefas, objetivos, sujeições e deveres de proteção do Estado. É neste sentido que os direitos-deveres socioambientais são direitos e deveres fundamentais, e como tais, gozam de tratamento privilegiado na ordem constitucional e nos tratados internacionais, albergados pelo ordenamento jurídico brasileiro. No espaço constitucional podemos encontrá-los de modo implícito ou explicito. Explicitamente são aqueles referidos expressamente no art. 225 da Constituição de 1988, ao contrário, os implícitos são irradiações ou decorrências da proteção ambiental, pois incorporam, além de os assegurarem, os atos de valoração ambiental, como o direito à vida, saúde, propriedade, informação, cultura, educação e ao exercício das ações constitucionais, entre outros, logo podemos falar de deveres socioambientais na dimensão objetiva e subjetiva, pois ora exigem a inação, ora a efetiva prestação dos seus destinatários (MOLINARO; RAMMÊ, 2015, p. 78).

Não podem ser olvidados, porém, os apontamentos de Kloepfer (2010), sobre os principais problemas que assolam a proteção estatal do ambiente: (a) ainda carece de aprofundamento doutrinário e jurisprudencial a adequada medida em que os direitos fundamentais dos destinatários das medidas estatais de proteção ambiental podem arrefecer ou mediar a proteção estatal do ambiente. Logo, não se pode admitir, uma posição aprioristicamente sempre favorável à proteção do ambiente, sob pena de submeter os cidadãos a uma ordem intervencionista de direito ambiental; (b) em Estados federados, não raro surgem problemas referentes à distribuição de competências em matéria ambiental, exigindo o aperfeiçoamento de um sistema federativo cooperativo no trato 
dessas questões; (c) a ampliação da proteção estatal do ambiente pode ocasionar problemas à democracia e ao Estado de Direito. Assim, a proteção do ambiente no âmbito legislativo esbarra na carência de formação técnico-científica dos legisladores. Ao mesmo tempo, muitas vezes quem detém o conhecimento técnico-científico necessário para a elaboração das normas definidoras de padrões ambientais são as próprias empresas destinatárias das normas, que oneram o ambiente. Isso faz com seja necessário tornar mais transparentes os procedimentos que dão origem aos padrões normativos ambientais, bem como os critérios e filosofias que os fundamentam. 0 mesmo problema se dá no âmbito das decisões judiciais, onde também não existem critérios claros sobre como se deve dar o assessoramento técnico-científico para a construção das decisões judiciais em matéria ambiental.

A democracia representativa também vem sendo colocada em cheque, diante da crescente resistência de parcelas da população frente a decisões estatais com efeitos potencialmente onerosos ao ambiente, sem que haja critérios claros de mediação e avaliação dos interesses atingidos. Esses problemas inegavelmente afetam e comprometem a tarefa estatal de proteção do ambiente. Daí a importância, cada vez mais evidente, de que o Estado (Socioambiental e Democrático de Direito) brasileiro, aperfeiçoe um sistema federativo cooperativo que incorpore valores ecológicos e de justiça ambiental; princípios materiais essenciais para a tutela do ambiente (precaução, prevenção, poluidor-pagador, proibição de retrocesso, gestão racional dos recursos, integração); bem como princípios instrumentais para o bom funcionamento do sistema federativo e da tarefa estatal de proteção ambiental (cooperação e subsidiariedade).

\section{CONSIDERAÇÕES FINAIS}

De todo o exposto, a interrogação que se oferece à reflexão é a seguinte: quais os limites e desafios que se 
impõem à intervenção coativa do Poder Judiciário frente ao descumprimento, pelos Poderes Executivo e Legislativo, das tarefas essenciais de proteção ao ambiente, seja pela ação seja pela omissão? Normalmente, uma análise dessa ordem perpassa pelo tema da discricionariedade administrativa e legislativa que, para muitos, limita a esfera de ingerência do Judiciário.

Contudo, cada vez mais perde força, em âmbito doutrinário e jurisprudencial, o entendimento de não ser possível buscar, junto ao Judiciário, a condenação da Administração Pública em obrigações de fazer, consistentes na adoção de medidas positivas de proteção do meio ambiente, tudo com base na impossibilidade de controle judicial do mérito administrativo (pautado pelo binômio "oportunidade e conveniência”), salvo se este ofender ao princípio da legalidade estrita. Do contrário, estar-se-ia permitindo ao Judiciário atuar como administrador, ferindo de morte o princípio da separação dos poderes. Assim, o controle judicial dos atos administrativos estaria adstrito ao exame das prescrições legais, expressamente determinadas.

A moderna noção de legalidade, pós Constituição de 1988, sofreu notável evolução, abarcando o que a moderna doutrina publicista define como "legalidade ampla", abarcando não apenas a observância à lei estrita mas a toda principiologia atinente ao regime jurídico-constitucional da proteção do ambiente, notadamente pela importância jusfundamental que adquiriu a tarefa estatal de proteção do ambiente.

No tocante especificamente à esfera de competência do Poder Executivo, não há falar em ingerência indevida do Poder Judiciário, ou mesmo ofensa ao princípio da separação dos Poderes, quando, diante de uma flagrante omissão ou desvio de sua tarefa-fim (jusfundamental) de proteção do ambiente, impõe à Administração Pública o cumprimento de obrigações de fazer que objetivem corrigir a proteção estatal insuficiente a determinado bem jurídico ambiental. Afinal não está o Judiciário, quando 
assim age, criando uma norma inexistente ou uma determinada política pública, penetrando no mérito administrativo e nas esferas da conveniência ou da oportunidade. Está, sim, impondo o cumprimento de uma obrigação pública objetiva implícita ou expressamente prevista na Constituição ou na legislação infraconstitucional.

Deve-se ter claro, portanto, que a discricionariedade administrativa está condicionada pela finalidade jurídico-constitucional do ato a ser praticado pela Administração, daí que o controle que se permite ao Judiciário realizar nesta seara é o controle finalístico da discricionariedade administrativa, podendo ser impostas à Administração, caso verificado o desvio de finalidade (na ação ou na omissão das políticas públicas adotadas), obrigações de fazer ou de não-fazer, sem caracterizar com isso ofensa à separação dos poderes. 0 mesmo ocorre com relação ao Poder Legislativo. Omissões legislativas ou mesmo legislações que se desviem da tarefa estatal de proteção do ambiente, notadamente quando reduzem ou flexibilizam a proteção ambiental já consolidada no plano normativo, também são passíveis de controle finalístico pelo Poder Judiciário.

O papel do Poder Judiciário, nesse particular, assume um viés corretivo. Como já destacado, o atual marco jurídico-constitucional brasileiro impõe ao Estado (Poder Público), em todos os níveis da federação, a tarefa de proteger o ambiente sadio e ecologicamente equilibrado para as presentes e futuras gerações. Esta tarefa envolve não apenas a proibição de interferir negativamente no ambiente, como também a obrigação de promover ações positivas, prestacionais, que garantam a eficácia e a efetividade do direito de todos ao ambiente sadio e equilibrado.

Disso resulta a possibilidade de reconhecer, via controle finalístico realizado pelo Poder Judiciário, a prática de condutas inconstitucionais (por ação ou por omissão), decorrentes da não adoção de medidas protetivas pelos Poderes Executivo e Legisla- 
tivo. Possível também reconhecer, além da possibilidade de o Judiciário impor ao Estado medidas concretas para sanar a omissão ou atuação insuficiente no âmbito da sua tarefa-fim de promoção e proteção do ambiente, a possibilidade de responsabilização judicial do Estado à reparação dos danos causados a indivíduos e grupos sociais afetados pelos efeitos negativos decorrentes da proteção estatal insuficiente em matéria ambiental.

Há que se atentar, porém, contra os perigos de um ativismo judicial que expresse uma postura interpretativa expansiva das normas constitucionais, para além marco constitucional estabelecido, externando um juízo claramente axiológico baseado nas convicções particulares do julgador. Trata-se de um limiteque não pode ser ultrapassado, sob pena de imporem-se sérios riscos à legitimidade democrática e à separação dos poderes. Especificamente à área ambiental, um desafio que se impõe ao Judiciário para o bom exercício do controle da proteção estatal insuficiente diz respeito à necessidade de aperfeiçoamento dos magistrados em áreas outras, diversas da ciência jurídica, já que o trato das questões ambientais invariavelmente exige do julgador conhecimentos interdisciplinares, para além dos conhecimentos meramente jurídico-dogmáticos.

\section{REFERÊNCIAS}

ALEXY, Robert. Teoria dos Direitos Fundamentais, Trad. de Virgílio Afonso da Silva. São Paulo: Malheiros, 2008.

BENJAMIN, Antônio Herman. Constitucionalização do ambiente e ecologização da constituição brasileira. In: CANOTILHO, José Joaquim Gomes; LEITE, José Rubens Morato (Org.). Direito Constitucional Ambiental Brasileiro, 2 ${ }^{a}$ ed. - São Paulo: Saraiva, 2008, p. 57-135.

CANOTILHO, José Joaquim Gomes. Direito constitucional ambiental português: tentativa de compreensão de 30 anos de gerações ambientais no direito constitucional português. In: CANOTILHO, José Joaquim Gomes; LEITE, José Rubens Morato (Org.). Direito Constitucional Ambiental Brasileiro.2 ${ }^{a}$ ed.São Paulo: Saraiva, 2008, p. 1-11. 
COURTIS, Christian. Derechos sociales, ambientales y relaciones entre particulares: nuevos horizontes. Bilbao: Universidade de Deusto, 2007.

ECHAVARRÍA, Juan José Solozábal. El derecho al medio ambiente como derecho público subjetivo. In: Studialuridica (81): A Tutela Jurídica do Meio Ambiente: Presente e Futuro, Coimbra, 2005, p. 33-45.

GIMÉNEZ, Teresa Vicente. Proyección de la justicia ecológica en la ordenación política y jurídica del medio ambiente. In: GIMÉNEZ, Teresa Vicente (Coord.). Justicia ecológica y protección del medio ambiente. Madrid: Editorial Trotta, 2002, p. 71-82.

GOMES, Carla Amado. Risco e modificação do acto autorizativo concretizador de deveres de protecção do ambiente.2007. $564 \mathrm{f}$. Tese (Doutorado em Ciências Jurídico-Políticas) - Faculdade de Direito. Universidade de Lisboa, Lisboa.

HESSE. Konrad. Temas fundamentais do direito constitucional. Textos selecionados e traduzidos por Carlos dos Santos Almeida, Gilmar Ferreira Mendes e Inocêncio Mártires Coelho. São Paulo: Saraiva, 2009. KLOEPFER, Michael. A caminho do Estado Ambiental? A transformação do sistema político e econômico da República Federal da Alemanha através da proteção ambiental especialmente desde a perspectiva da ciência jurídica. Trad. de Carlos Alberto Molinaro. In: SARLET, Ingo Wolfgang (Org.). Estado socioambiental e direitos fundamentais. Porto Alegre: Livraria do Advogado, 2010, p. 39-72.

KRELL, Andreas Joachim. Comentário ao art. 225, caput. In: CANOTILHO, J. J. Gomes; MENDES, Gilmar F.; SARLET, Ingo W.; STRECK, Lenio L. (Coords.). Comentários à Constituição do Brasil. São Paulo: Saraiva/ Almedina, 2013, p. 2078-2087.

LEFF, Enrique. Los derechosdel ser colectivo y lareapropiación social de lanaturaleza: a guisa de prólogo. In: LEFF, Enrique (Coord.). Justicia Ambiental: construción y defensa de losnuevosderechosambientales, culturales y colectivosen América Latina. México: PNUMA, 2001, p. 7-33.

MENDES, Gilmar Ferreira. Direitos Fundamentais e controle de constitucionalidade. 3. ed. São Paulo: Saraiva, 2004.

MIRANDA, Jorge. Manual de Direito Constitucional, Tomo IV - Direitos Fundamentais, 3a ed. Coimbra: Almedina, 2000. 
MOLINARO, Carlos Alberto; RAMMÊ, Rogério Santos. Os deveres de proteção do Estado em matéria ambiental e o controle judicial de proteção insuficiente. Revista de Direito Ambiental, v. 20, 2015, p. 61-102.

NABAIS, José Casalta. 0 dever fundamental de pagar impostos: contributo para a compreensão do estado fiscal contemporâneo. Coimbra: Almedina, 2009.

PEREIRA DA SILVA, Vasco. Verde cor de direito: lições de Direito do Ambiente. Coimbra: Almedina, 2002.

PÉREZ LUÑO, Antonio-Enrique. Derechos humanos, Estado de Derecho y Constituición. 9a ed. - Madrid: Tecnos, 2005.

. Perspectivas e tendências atuais do Estado Constitucional. Porto Alegre: Livraria do Advogado Editora, 2012.

SARLET, Ingo Wolfgang. Dignidade da pessoa humana e direitos fundamentais na Constituição Federal de 1988. 9ạ ed. - Porto Alegre: Livraria do Advogado, 2012.

SARLET, Ingo Wolfgang; FENSTERSEIFER, Tiago. Estado socioambiental e mínimo existencial (ecológico?): algumas aproximações. In: SARLET, Ingo Wolfgang (Org.). Estado socioambiental e direitos fundamentais. Porto Alegre: Livraria do Advogado, 2010, p. 11-38.

; FENSTERSEIFER, Tiago. Deveres fundamentais ambientais.

Revista de Direito Ambiental, n. 67. São Paulo: Revista dos Tribunais, 2012, p. 11-70.

; FENSTERSEIFER, Tiago. Direito Constitucional Ambiental,

3a ed.São Paulo: Revista dos Tribunais, 2013.

TRINDADE, Antônio Augusto Cançado. Direitos humanos e meio ambiente: paralelo dos sistemas de proteção internacional. Porto Alegre: Sérgio Antônio Fabris, 1993.

VIEIRA DE ANDRADE, José Carlos. Os direitos fundamentais na Constituição Portuguesa de 1976. 5ª ed.- Coimbra: Almedina, 2012.

YARZA, Fernando Simón. Medio ambiente y derechosfundamentales. Madrid: CEPC, 2012. 